\title{
Patients Satisfaction With The Dental Treatment Provided At The University of Jordan Students Clinics
}

Noor H. Ismail ( $\sim$ Noor.ismail26@yahoo.com )

University of Jordan

Heba Alzer

University of Jordan

Amena H Algurini

King Hussein Medical Center

Dina H Alsawalhi

King Hussein Medical Center

Sarah M. Hait

Ministry of Health

Firas Alsoleihat BDS

University of Jordan

Summer J. Mahmoud

King Hussein Medical Center

\section{Research Article}

Keywords: Dental care, undergraduate dental students, patients' satisfaction, Dental Satisfaction Questionnaire, dental student clinics

Posted Date: December 21st, 2021

DOI: https://doi.org/10.21203/rs.3.rs-1153823/v1

License: (a) (1) This work is licensed under a Creative Commons Attribution 4.0 International License. Read Full License 


\section{Abstract}

Objectives: To assess patients' satisfaction with the dental care provided to them by the undergraduate students at Jordan University Hospital.

Methods: The Dental Satisfaction Questionnaire (DSQ) developed by the RAND Corporation was used to measure patient satisfaction. The questionnaire was translated to Arabic the native language of the country and it consisted of 14 questions, which measure the overall satisfaction and the subscales of access, convenience \& availability, continuity of treatment, and quality of dental care provided.

Results: A total of 94 patients (58.5\% female, $41.5 \%$ male) answered the DSQ, the Overall Dental Satisfaction Index (DSI) was found to be $86.2 \%$, and there was no correlation between gender or age groups with the DSI $(P<0.05)$. The lowest score $(3.7 / 5)$ was given to the question about whether the school building and dental units being modern and well equipped.

Conclusions: Patients who were treated at the student clinics at the University of Jordan, School of Dentistry were mostly satisfied about the treatment provided, the main cause for dissatisfaction was the clinics building that is very old and crowded, and the lack of modern dental units and equipment.

\section{Introduction}

Dentistry is a patient centered profession which makes patients satisfaction about the service provided a key factor for a successful career. Patients opinion sheds a light over aspects of the dental teaching program that might otherwise be missed by the faculty. It could also be a major indicator on how well dental programs are running and if they are achieving positive work in the community that they are part of. The information obtained through a patient satisfaction study can be used to improve the quality of the program and to implement patient centered care where patients' needs and chief complaint are the drive for the treatment provided $(1,2)$.

Practicing dentistry during the COVID-19 pandemic has been very challenging, leading to increased levels of stress and anxiety between dentists due to the high risk of getting infected (3-6). This stress could have affected the way dental students treated their patients during clinical training, in addition to the reduction of clinical time provided to them, due to the nationwide lockdowns that happened at the time. Patients who attended the dental student clinics have also been affected by the pandemic, for example, social distancing was implemented in the waiting area, rapid testing for COVID-19 became a requirement at each visit, and the course of treatment was interrupted due to the lockdown.

The comprehensive care model, that has been adopted by most dental schools (7-9), is where students manage the patients based on chief complain and priority of treatment needs; meaning they start by addressing any urgent treatment needed followed by conservative management and finally prosthetic treatment. The undergraduate dental students at the University of Jordan treat patients that need simple fixed prosthetic work as part of their final year training. Case selection is performed by faculty members 
to make sure the cases suit the students' level of expertise. The students are supervised throughout their work by qualified faculties from different specialties.

In this study patients who were treated by the undergraduate students for fixed prosthetic work were asked to fill out the Dental Satisfaction Questionnaire (DSQ) developed by RAND Corporation (10), to measure their satisfaction about the treatment provided to them by the undergraduate dental students.

The importance of this study lays in the fact that no previous studies investigated patients' satisfaction with the treatment provided at the schools of dentistry in Jordan. Furthermore, the treatment which was provided during this study happened under exceptional conditions caused by the COVID-19 pandemic which might influenced patients' satisfaction.

\section{Methods}

Patients who were treated by the undergraduate dental students were asked to fill a survey form, the inclusion criteria involved all patients who have been treated during the school year 2020/2021 by the final year undergraduate dental students, received a fixed prosthetic work as part of their treatment, and completed the full course of the treatment needed. Patients who were treated for other dental procedures without having fixed prosthetic work during the course were excluded from the study. Ethical approval was obtained from the academic research committee at The University of Jordan. Informed consent was obtained form the participants and the study was carried out in accordance to the regulations and guidelines of the ethical committee.

The Dental satisfaction questionnaire (DSQ) which was developed by The RAND Corporation in 1982, was found suitable to be used in our study to measure patient satisfaction, it uses a 5-point Likert scale "strongly agree, agree, not sure, disagree, strongly disagree" to measure the subscales "Access, availability \& convenience, continuity, and quality of treatment" along with the overall dental satisfaction index (DSI). Some modifications were made to the original questionnaire to suit our program as in; the questionnaire was translated to Arabic the native tongue of the Jordanian population, and the part about cost was excluded since treatment is provided for free at the student clinics, and the part about pain management was also excluded since dental pain is managed at the dental emergency clinic. The questionnaire consisted of 14 questions which covered the subscales along with additional questions that were added about patients age \& gender, and an open-ended question at the end of the questionnaire about any further comment patients have about the treatment provided.

The data was entered into a Microsoft excel sheet, and the responses were coded as $1=$ strongly agree, $2=$ agree, $3=$ not sure, $4=$ disagree, $5=$ strongly disagree for all questions except for the questions numbered " $1,2,8,11,14$ " which were coded the opposite way so that for each question the higher the score the more favorable the results are. The scaled mean is written as a number out of 5 for each category, and the prorated mean which is the raw mean expressed as a percent for each subscale from the highest score possible in that scale. Both means were calculated in addition to the overall dental satisfaction index which is the calculated mean for all the questions combined. Statistical analysis was performed using 
IBM SPSS version 28. Mann Whitney $\mathrm{U}$ test was performed to analyze correlation between gender and patients' overall satisfaction, since the data was not normally distributed. One-Way ANOVA test was used to study correlation between age and patients' overall satisfaction. Statistical significance was put at the 0.05 probability level in both tests.

\section{Results}

A total of 94 patients who were treated by our undergraduate students and matched the criteria answered the DSQ. The percentage of females to males who participated in the study along with the type of fixed prosthetic treatment they received are shown in (Table 1). All 14 questions were filled by all patients with no missing data, except for 5 patients who refused to announce their age. The mean score for each individual question is shown in (Table 2) the higher the score out of 5 the more favorable the rating is. The dataset generated in this study is available as a supplementary file under the title "DSQ data".

Table 1

The gender of the participants and the type of fixed prosthetic treatment they received.

\begin{tabular}{|lll|}
\hline Gender & Female & $\mathbf{5 8 . 5 \%}$ \\
\hline & Male & $41.5 \%$ \\
\hline Type of Fixed prosthesis & Fixed - Fixed conventional Bridge & $77.7 \%$ \\
\hline & Single Crown & $21.3 \%$ \\
\hline & Cantilever bridge & $1 \%$ \\
\hline
\end{tabular}


Table 2

The DSQ questions along with their individual scaled mean values out of five and their standard deviations.

\begin{tabular}{|c|c|c|}
\hline Subscale & Question & $\begin{array}{l}\text { Mean } \\
(\text { Std) }\end{array}$ \\
\hline \multirow[t]{3}{*}{ Access } & 1. The waiting period before the appointment is too long & $\begin{array}{l}4.5 \\
(0.9)\end{array}$ \\
\hline & $\begin{array}{l}\text { 2. It's difficult to book an appointment to be treated in the dental student } \\
\text { clinics }\end{array}$ & $\begin{array}{l}4.2 \\
(1.1)\end{array}$ \\
\hline & $\begin{array}{l}\text { 3. The office hours for the student clinics are convenient and suits most } \\
\text { people }\end{array}$ & $\begin{array}{l}4.2 \\
(1.1)\end{array}$ \\
\hline \multirow[t]{2}{*}{ Availability } & 4. There are adequate number of dental students to treat patients & $\begin{array}{l}4.2 \\
(1.0)\end{array}$ \\
\hline & 5. The location of the student clinics is convenient and easy to reach & $\begin{array}{l}4.2 \\
(1.0)\end{array}$ \\
\hline \multirow[t]{7}{*}{ Quality } & 6. The dental students were careful to check everything during examination & $\begin{array}{l}4.6 \\
(0.8)\end{array}$ \\
\hline & 7. The dental students treat patients with respect & $\begin{array}{l}4.9 \\
(0.2)\end{array}$ \\
\hline & 8. The dental student is not very thorough in his/her examination & $\begin{array}{l}4.2 \\
(1.2)\end{array}$ \\
\hline & 9. The student was able to treat or manage most of my dental problems & $\begin{array}{l}4.4 \\
(0.9)\end{array}$ \\
\hline & $\begin{array}{l}\text { 10. The student goes into details and explains the treatment plan at each } \\
\text { stage very well }\end{array}$ & $\begin{array}{l}4.7 \\
(0.6)\end{array}$ \\
\hline & $\begin{array}{l}\text { 11. Dental students should spend more time giving oral hygiene } \\
\text { instructions and how to prevent dental diseases }\end{array}$ & $\begin{array}{l}4.6 \\
(0.7)\end{array}$ \\
\hline & 12. Student clinics are very modern and well equipped & $\begin{array}{l}3.7 \\
(1.2)\end{array}$ \\
\hline Continuity & 13. I was treated by the same student every time I came to the clinic & $\begin{array}{l}4.6 \\
(0.9)\end{array}$ \\
\hline $\begin{array}{l}\text { General } \\
\text { satisfaction }\end{array}$ & 14. There are things about the dental care that could be improved & $\begin{array}{l}3.2 \\
(1.6)\end{array}$ \\
\hline
\end{tabular}

The mean, standard deviation, scaled mean and prorated mean for each subscale along with the overall dental satisfaction index are all shown in (Table 3), higher score reflects a more favorable rating. 
Table 3

The mean (Standard deviation), scaled mean, and prorated mean for the subscales and the overall dental satisfaction index.

\begin{tabular}{|llll|}
\hline Subscale & Number of related questions & Scaled mean (out of 5) & Prorated mean \\
\hline Access & 3 & 4.3 & $86.7 \%$ \\
\hline Availability & 2 & 4.2 & $83.8 \%$ \\
\hline Quality & 7 & 4.5 & $89.1 \%$ \\
\hline Continuity & 1 & 4.6 & $92.5 \%$ \\
\hline General satisfaction & 1 & 3.2 & $63.8 \%$ \\
\hline Overall DSI & 14 & 4.3 & $86.2 \%$ \\
\hline
\end{tabular}

Mann Whitney $U$ test showed no significant difference between gender and the overall DSI $(P>0.05)$. Using the One-Way ANOVA test, no significant difference was found between the different age groups and the DSI $(P>0.05)$. The mean DSI for each age group is show in (Table 4).

Table 4

The age groups of the patients and their mean DSI.

\begin{tabular}{|lll|}
\hline & Number of patients & Scaled Mean \\
\hline$<20$ & 4 & 4.3 \\
\hline $21-30$ & 26 & 4.2 \\
\hline $31-40$ & 30 & 4.4 \\
\hline $41-50$ & 21 & 4.3 \\
\hline $51-60$ & 7 & 4.2 \\
\hline$>61$ & 1 & 4.7 \\
\hline Total & 89 & 4.3 \\
\hline
\end{tabular}

The answers for the open-ended question were reviewed and the phrases that were common in their answers were: old building, crowded floor, not very modern, lack of space, old dental units.

\section{Discussion}

Patients satisfaction about the treatment provided by the undergraduate students is one of the indicators about the quality of the program, since high patients satisfaction indicates that the students are able to provide their patients with the required treatment, it also indicates more patients will be joining the program to be treated in the future, which secures the continuity of adequate dental training to the undergraduate students. Student Dental clinics provide community service by treating patients for no or low cost, and it's important for the dental school to monitor the quality of the service provided. 
The study was carried at the beginning of the second semester 2020/2021 and included patients who received fixed prosthetic work and completed their full treatment plan in multiple visits, making sure that they attended the clinic for several visits and accordingly they experienced advanced management by the students and were able to scale and judge all the conditions they were asked about in the DSQ. The DSQ which was developed by RAND Corporation was chosen as our tool of investigation since its reliability and validity has been tested and was reported in the literature several times (10-13).

The majority of patients received a Fixed-Fixed conventional Bridge (77.7\%), to replace missing teeth with some receiving cuspal coverage in the form of single crowns $(21.3 \%)$, and only few patients received cantilever bridge (1\%), The construction of these prosthesis would've required a minimum of 5 visits to finish in addition to prior control phase to treat any tooth decay or periodontal disease patients might have, hence the patients that we included in our study have been exposed to many procedures and spent adequate time at the student clinics to give us a fair opinion.

The results obtained showed high patients satisfaction with the lowest scores given to questions about the student clinics being modern and well equipped (3.7/5) and if some aspects of the dental care could be improved (3.2/5) when patients were asked about their answers in the open-ended questions they explained that they felt the building was very old and the dental units were not very modern compared to private clinics, they also found the floor where the clinics are situated to be crowded and discouraging.

All subscales (Access, availability, quality, continuity, and general satisfaction) have scored above 3 which indicates high patients' satisfaction. The general satisfaction subscale scored the lowest with (3.2/5) which was attributed to the dissatisfaction about the building and the lack of modern units in the clinics. The high score could be attributed to the lack of fees which could mean that patients have lower expectations and feel appreciative to the treatment provided, or that they consider the dental treatment provided by students under the close supervision of trained specialist to be better quality than in other places. The same conclusion was reached by a study conducted at Ohio State University (7) which obtained high satisfaction scores by the patients treated at their student clinics. Another possible reason for the high scores is the fact that the study was conducted during COVID-19 pandemic, shortly after the return of clinical teaching which led the patients to feel appreciative that the students were providing treatment to them under new and stressful conditions.

Neither the gender of the patients nor the age affected the overall patients' satisfaction which is probably due to the kind of treatment they received (fixed prosthesis); that made the clinical conditions they went through to be alike and unaffected by the age or the gender of the patient in this case.

The results of this study were comparable to the results reported by other schools of Dentistry at The University of the West Indies which scored a $76.42 \%$ for the overall DSI (13), and The Louisiana State University where more than $90 \%$ of participants gave positive response and stated the low cost of treatment as the most frequent cause for attending the clinic (14). The study that was conducted by the University of Louisville which included active and old patients whom were interviewed using the telephone, found patients who dropped out of care to be less satisfied than active patients (15), this could 
explain the high satisfaction percentage in our study since only active patients were included. Another study which was conducted at the Lagos State University Dental Clinic (12) found the communication with the patients and the waiting time to be the main reason for dissatisfaction by the patients. The literature shows that patients' satisfaction by the treatment provided by student clinics is mostly on the positive side of the scale, with only few issues found to be unsatisfactory for each school.

\section{Conclusions}

Patients who were treated at the student clinics at the University of Jordan, School of Dentistry were mostly satisfied about the treatment provided, the main cause for dissatisfaction was the clinics building that is very old and crowded, and the lack of modern dental units and equipment.

\section{Declarations}

\section{Ethical approval}

Ethical approval was obtained from the academic research committee at The University of Jordan

\section{$\underline{\text { Conflict of interest }}$}

The authors declare no conflict of interest related to this study.

Data availability.

The datasets generated during and analyzed during the current study are available within the article and its supplementary information files

\section{Funding}

This research received no specific grant from any funding agency in the public, commercial, or not-forprofit sectors.

\section{Authors' contributions}

N.l: structuring the study and drafting the final manuscript

A.A. , D.A., S.M., S.H.: acquisition of the data and interviewing the participants, along with helping in the interpretation of results

H.A, F.A: revising the work critically for important intellectual content and carrying the statistical analysis

Acknowledgment

Not applicable 


\section{References}

1. Newsome PR, Wright GH. A review of patient satisfaction: 1. Concepts of satisfaction. British Dental Journal. 1999;186 (4 Spec No).

2. Evangelidis-Sakellson V. Student productivity under requirement and comprehensive care systems. Journal of Dental Education. 1999;63(5).

3. Noor H Ismail YO, Ayah A Al-Asmar, Islam Abd Al-Raheam, Ala'a Sabrah. The Change in Stress and Anxiety Level Caused by Practicing Dentistry During COVID-19 Pandemic. Jordan Medical Journal. 2021;55(1).

4. De Stefani A, Bruno G, Mutinelli S, Gracco A. COVID-19 Outbreak Perception in Italian Dentists. Int J Environ Res Public Health. 2020;17(11).

5. Uhlen MM, Ansteinsson VE, Stangvaltaite-Mouhat L, Korzeniewska L, Skudutyte-Rysstad R, Shabestari M, et al. Psychological impact of the COVID-19 pandemic on dental health personnel in Norway. BMC Health Serv Res 21, 420 (2021).

6. Ahmed MA, Jouhar R, Ahmed N, Adnan S, Aftab M, Zafar MS, et al. Fear and Practice Modifications among Dentists to Combat Novel Coronavirus Disease (COVID-19) Outbreak. Int J Environ Res Public Health. 2020;1 (8)

7. Mascarenhas AK. Patient Satisfaction with the Comprehensive Care Model of Dental Care Delivery. Journal of Dental Education. 2001;65(11).

8. Holmes DC, Trombly RM, Garcia LT, Kluender RL, Keith CR. Student productivity in a comprehensive care program without numeric requirements. Journal of Dental Education. 2000;64(11).

9. Johnson G. A comprehensive care clinic in Swedish dental undergraduate education: 3-year report. Europian Journal of Dental Education. 1999;3(4).

10. Davies AR, Ware JE. Development of a Dental Satisfaction Questionnaire for the Health Insurance Experiment. Santa Monica, CA: The Rand Corporation; 1982.

11. Golletz D, Milgrom P, Mancl L. Dental care satisfaction: the reliability and validity of the DSQ in a lowincome population. Journal of Public Health Dentistry. 1995;55(4).

12. Adeniyi AA, Adegbite KO, Braimoh MO, Ogunbanjo BO. Factors affecting patient satisfaction at the Lagos State University Teaching Hospital Dental Clinic. Afr J Med Med Sci. 2013;42(1..

13. Balkaran RL, Osoba T, Rafeek R. A Cross-sectional Study of Patients' Satisfaction with Dental Care Facilities: A Survey of Adult Treatment at The University of the West Indies, School of Dentistry. West Indian Med J. 2014;63(5).

14. Lafont BE, Gardiner DM, Hochstedler J. Patient satisfaction in a Dental School. European Journal of Dental Education. 1999;3(3).

15. Butters JM, Willis DO. A comparison of patient satisfaction among current and former dental school patients. Journal of Dental Education. 2000;64(6).

\section{Supplementary Files}


This is a list of supplementary files associated with this preprint. Click to download.

- DSQdata.xIsx 